\title{
GPs' role in safeguarding children
}

\author{
Jenny Woodman PhD research student ${ }^{1}$, Simon de Lusignan professor of primary care and clinical \\ informatics ${ }^{2}$, Imran Rafi medical director, Clinical Innovation and Research Centre ${ }^{3}$, Janice Allister \\ clinical champion for child health ${ }^{3}$, Ruth Gilbert professor of clinical epidemiology ${ }^{1}$
}

${ }^{1} \mathrm{MRC}$ Centre of Epidemiology for Child Health, UCL-Institute of Child Health, London WC1N 1EH, UK; ${ }^{2}$ Department of Health Care Management and Policy, University of Surrey, Guilford, UK; ${ }^{3}$ Royal College of General Practitioners, London, UK

The debate between Spence and Masters about whether the modern GP is a key player in safeguarding children from abuse and neglect risks polarising this discussion and wasting the opportunity to make better use of the systems we have. ${ }^{1}$

Child maltreatment is common and often chronic, but many affected children only occasionally, or never, reach the threshold for investigation or intervention by child protection services. ${ }^{2}$ The health professional's role must therefore go beyond identification and referral to social care to include a breadth of responses. This includes recording concerns in the electronic health record, discussing the matter with colleagues, monitoring, information gathering, and, for GPs, regular practice meetings to discuss management of vulnerable families. ${ }^{3}$ GPs, unlike teachers or other health professionals, see multiple family members and can identify risk factors in the parents, such as substance misuse or mental health problems. A Danish study found that more than half of the cases of a child in need discussed by participating GPs had come to their attention through consultations with the parents and subsequent reflection. ${ }^{4}$

Even if modern GPs do not know families in the way they used to, consistent data recording would support the continuity of care and build up a cumulative picture of concern. On the basis of a collaborative project with the Royal College of General Practitioners, we propose a simple and feasible way to improve recording of safeguarding concerns in electronic GP records, ${ }^{5}$ with a pragmatic and easy to use recommended coding list available at: www.clininf.eu/childmaltreatment-codes.html.

Competing interests: None declared.

1 Masters NJ. What is the role of GPs in safeguarding children? BMJ 2012;344:e4123. (19 June.)

2 Gilbert R, Kemp A, Thoburn J, Sidebotham P, Radford L, Glaser D, et al. Recognising and responding to child maltreatment. Lancet 2009;373:167-80.

3 Royal College of General Practitioners. Safeguarding children and young people: a toolkit for general practice. 2011. www.rcgp.org.uk/clinical_and_research/safeguarding_children_ tookit.aspx.

4 Hølge-Hazelton B, Tulinius C. Beyond the specific child. What is "a child's case" in general practice? Br J Gen Pract 2010;60:e4.

5 Woodman J, Allister J, Rafi I, de Lusignan S, Belsey J, Petersen I, et al. Simple approaches to improve recording of concerns about child maltreatment in primary care records: developing a quality improvement intervention. Br J Gen Pract 2012;62:e478-86.

Cite this as: BMJ 2012;345:e4758

(๑) BMJ Publishing Group Ltd 2012 